\title{
INSTRUMENTOS DA ADMINISTRAÇÃO CONSENSUAL. A AUDIÊNCIA PÚBLICA E SUA FINALIDADE*
}

\section{LUCIA VALLE FIGUEIREDO**}

I- A Constituição de 1988 e a audiência pública - II - Os Princípios Específicos da Licitação - III - Invalidação do Procedimento em virtude da audiência pública viciada: falta de razoabilidade, falta de motivação elou fatos supervenientes, que poderiam possibilitar escolhas administrativas diferentes

\section{I - A Constituição de 1988 e a audiência pública}

1. A Constituição de 1988 , inequivocamente, pretendeu que a democracia se realizasse por meio dos representantes eleitos pelo povo, mas, também, diretamente, nas formas permitidas por ela própria.

Assim, no capítulo referente ao Meio-Ambiente, vez primeira introduzido na Constituição de 1988, consagrou-se para as obras, que pudessem provocar impacto no meio-ambiente, a obrigatoriedade do estudo de impacto ambiental, ao qual se daria ampla publicidade, naturalmente com a participação pública.

$\mathrm{O}$ art. $74, \S 2^{\circ}$ da Constituição outorgou a qualquer cidadão, partido político, associação ou sindicato, legitimidade para denunciar irregularidades ou ilegalidades perante o Tribunal de Contas.

$\mathrm{O}$ art. 31 da Constituição, $\S 3^{\circ}$, determinou que as contas municipais ficassem à disposição para que, qualquer contribuinte, pudesse fiscalizá-las.

$\mathrm{O}$ art. 37, referente à Administração Pública, também, pela primeira vez, trouxe inseridos, diretamente na Constituição, como princípios expressos, os da publicidade e moralidade.

* Trabalho realizado para o Seminário em homenagem ao Professor García de Enterría (Rio de Janeiro, outubro de 2001).

** Professora Titular de Direito Administrativo da PUC - São Paulo. Juíza aposentada do Tribunal Regional Federal da 3* Região. Advogada e Consultora Jurídica em São Paulo. 
José Afonso da Silva, ao se referir ao direito de participação, distingue-o da seguinte forma: (1) participação direta (direito ao processo decisório), (2) participação orgânica, como a dos trabalhadores, empresários e aposentados na gestão da seguridade social, e, finalmente, (3) direito de participação da comunidade. Traz. como exemplo exatamente o art. $31 . \S 3^{\circ}$ da Constituição, já citado por nós.

É a defesa do interesse público, da coletividade. A audiência pública, que nos propormos tratar, é autêntico direito difuso. Não se trata de direito individual, porém de direito público subjetivo de defesa da comunidade, somente reflexamente poderá ser direito individual.

É pertinente ao interesse de todos e de cada um, de cada um e de todos.

\section{A audiência pública na Lei 8.666/93 (Lei de Licitações e Contratos)}

Foi editada a Lei 8.666/93 (posteriormente modificada por diversas vezes) sob esse novo clima constitucional, que consagrou. às abertas, a participaçâo popular. como vimos.

$\mathrm{Na}$ Lei 8.666/93, lei que disciplina as Licitações e Contratos, vemos vários dispositivos consignadores da participação popular.

Repete a Lei 8.666/93, didaticamente, consoante se nos afigura, a participação popular no controle das licitações, com a conseqüente consagração da cidadania. Isso verificamos nos artigos que serão reproduzidos em seguida, com as modificações sucedidas ulteriormente.

Inicialmente, temos o art. $4^{\circ}$ da Lei de Licitaçôes e Contratos, possibilitando a qualquer cidadão o acompanhamento do procedimento licitatório.

Em seguida, o art. $7^{\circ}, \S 8^{\circ}$, vai permitir que qualquer cidadão possa requerer à Administração Pública os quantitativos das obras e preços unitários de determinada obra executada:

Também, no art. $15, \S 6^{\circ}$, está escrito:

“Art. 15 - As compras, sempre que possível, deverão:

(...)

$\S 6^{\circ}$. Qualquer cidadão é parte legítima para impugnar preço constante do quadro geral em razão de incompatibilidade desse com o preço vigente no mercado".

3. Porém, é no art. 39, que se encontra o ápice da participação popular, quando determina a Lei a necessidade de audiência pública para licitações de grande vulto, ali definidas.

A audiência pública, se não efetuada, quando ocorrente o pressuposto descrito na norma. invalida a licitação. E, se assim é, poder-se-ia questionar se o resultado dessa audiência seria ou não vinculante ao administrador.

Apesar de obrigatória, não é vinculante, consoante se nos afigura, por ausência de determinação legal para tal fim. $O$ administrador poderá justificar a necessidade 
de realização da obra ou serviço da maneira pretendida, e realizá-los. Todavia, como se poderá inferir, passa ser questionável a legitimidade de obra ou serviço recusados pela comunidade, ou, mesmo, questionados, até, às vezes, no tocante à maneira de realizá-los.

3.1. Destarte, a primeira grande consequência, verificada por nós: inverte-se, em termos de controle, o ônus da prova.

Há necessidade de a Administração provar que sua decisão, não obstante desacolhida ou questionada pela comunidade interessada, ou acolhida em outros termos, foi bem tomada. Nota-se, em conseqüência, a presunção de que a obra ou o serviço poderia entrar em atrito com os princípios vetoriais da Administração Pública.

Assinale-se, também, que a norma prevê a possibilidade de acesso de qualquer interessado à audiência pública. E, obviamente com direito à participação efetiva.

3.2. O Professor Agustín Gordillo, em palestra proferida no IV Congresso Internacional de Direito Administrativo, realizado em Foz de Iguaçu, há longo tempo, em agosto de 1994, portanto, logo após à edição da Lei, compartilhou do entendimento de se ter introduzido, muito oportunamente, às claras, às abertas, a participação popular.

$\mathrm{O} \S 1^{\circ}$ do art. 41 prescreve a possibilidade de qualquer cidadão impugnar edital de licitação².

A Administração deverá necessariamente "julgar e responder à impugnação", em até três dias.

É claro que a Administração deveria responder, com ou sem lei, considerando-se sua competência, o exercício de função. Porém, também é verdade que, se não houvesse lei, com o nosso "caldo" de cultura, nem sequer seria protocolado o pedido, compelindo-se o cidadão, obrigatoriamente, a se utilizar das vias judiciais.

Ainda, o art. 63 permite a qualquer licitante o conhecimento dos termos do contrato e do respectivo processo licitatório, e a qualquer interessado a obtenção de cópia autenticada do mesmo ${ }^{3}$.

E, finalmente, o art. $113, \S 1^{\circ}$, redundante, pleonástico, afirma:

2 "Art. 41. A Administração não pode descumprir as normas e condições do edital ao qual se acha estritamente vinculada.

$\S 1^{\circ}$. Qualquer cidadão é parte legítima para impugnar edital de licitação por irregularidade na aplicação desta lei, devendo protocolar o pedido até 5 (cinco) dias úteis antes da data fixada para abertura dos envelopes de habilitação, devendo a Administração julgar e responder à impugnação em até 3 (três) dias úteis, sem prejuízo da faculdade prevista do $\S 1^{\circ}$ do art. 113 .

(...)."

3 A objeção (não nossa) é de que tal possibilidade defluiria imediatamente do princípio da publicidade. consagrado constitucional e legalmente. Todavia, a vingar tais argumentos, acreditamos desnecessária a explicitação constitucional dos direitos e garantias individuais e coletivos, vez que bastaria estar assegurado o princípio da igualdade. da participação popular, da separação dos Poderes e do direito à jurisdição. Lembramos de inúmeras palestras. em que nosso querido mestre Seabra Fagundes afirmava a necessidade de Constituição analítica, cm nosso momento histórico e de nenhuma tradição de respeito às leis. 
" $\S 1^{\circ}$. Qualquer licitante, contratado ou pessoa física ou jurídica poderá representar ao Tribunal de Contas ou aos órgãos integrantes do sistema de controle interno contra irregularidades na aplicação desta lei, para os fins do disposto neste artigo."

Nesse artigo, de fora a parte o pleonasmo, a enorme redundância, vê-se ampliada a possibilidade constitucional do $\S 2^{\circ}$ do art. 74 , que somente atribuía aos sindicatos, partidos políticos, associações e ao cidadão o direito de representar aos Tribunais de Contas.

Como se verifica da amostragem tópica, o controle das licitações passou a ser exercido, via de regra, também pelo povo, de quem emana todo poder na res publica.

4. Pretende-se demonstrar, pois, que o desiderato constitucional, seguido de perto pela legislação específica, foi o de transparência da Administração Pública e com a efetiva participação popular, tão importante para o concerto entre administração e administrado.

5. Costumam dizer os monografistas do tema Licitação, que o procedimento licitatório começa para o público com a publicação do edital.

Deve-se fazer a isso grave reparo. O início não é com a publicação do edital, caso as obras e os serviços exijam expressamente audiência pública preliminarmente, pois, se assim for, o inicio do procedimento dar-se-á com a audiência pública, portanto, já não mais com o edital.

Aliás, se o procedimento administrativo determinar que sejam as decisões administrativas precedidas de audiência pública, essa deve se constituir na fase inicial de procedimento.

Deveras, como se verifica, se a deflagração do procedimento verifica-se com a audiência pública (repetimos, para determinadas obras de vulto), esta será, sem dúvida, a fase inicial do procedimento.

6. Já conceituamos procedimento da seguinte forma, afirmando ser a palavra polissêmica:

"Vemos, portanto, que o termo "procedimento" emprega-se em duas acepções bastante diferenciadas. Ora refere-se ao conjunto de formalidades necessárias para emanação de atos administrativos, ora como a sequiência de atos administrativos, cada qual per se desencadeando efeitos típicos (como, no exemplo citado, procedimentos concorrenciais, concurso, licitação), porém todos tendentes ao ato final, servindo-lhe de suporte de validade.

No primeiro caso - conjunto de formalidades - há uma série de atos, inclusive de terceiros, e fatos administrativos necessários à formação válida do procedimento." 4

4 Curso de Direito Administrativo, $5^{*}$ edição. Malheiros Editores, São Patilo. 2001. cap. XV. 
7. Utilizando-nos da teoria da linguagem, podemos afïrmar que a audiência pública é um evento, que, depois, feita a competente ata documentando-o, passa a ser relevante para o direito cono fato administrativo, pois jurisdicizado, e absolutamente necessário para compor o procedimento, a preceder — nesses casos assinalados - $\mathrm{o}$ ato administrativo do edital. Portanto, temos a necessidade de um fato jurídico preliminar ao edital para validá-lo, fato jurídico este que será documentado pela Ata da Audiência. esta constituindo-se no ato administrativo inicial do procedimento.

E não se poderá considerar a audiência pública como. uma formalidade a mais apenas, sem qualquer relevância, pois, como já procuramos anteriormente demonstrar, quer na Constituição de 1988, quer na própria Lei 8.666/93, há enorme importância na participação popular.

8. Deve-se proscrever, portanto, a possibilidade de que qualquer evento, denominado audiência pública seja hábil a validar o edital, tal seja, o próprio procedimento licitatório. E, por isso mesmo, não se poderá permitir que medeie largo tempo entre a audiência e a publicação do edital ${ }^{5}$.

Hábil a validar o edital será a audiência pública que cumpra sua finalidade básica de informar a obra ou serviço a ser contratado, qual a forma pela qual será executado e o porquê de ter sido escolhida tal ou qual técnica, tudo isso com fundamentação suficiente.

Ademais, os participantes da audiência devem ter ampla liberdade de se manifestar e tentar demonstrar se a técnica é boa ou não, porque sim e/ou porque não, ou, se haveria viabilidade de ser feita ou melhor executada em outra técnica.

A Administração deverá, então, demonstrar quais os motivos que levaram a sua decisão, à escolha feita. declarando expressamente sua motivação para a escolha.

Já tivemos a oportunidade de, inúmeras vezes, dizer que a discricionariedade do administrador está balizada.

8.1. A finalidade da audiência pública é a publicidade, nesta entendida a possibilidade de participação ampla dos cidadãos. E de os interessados, ao fim e ao cabo, rejeitarem ou aprovarem o que tiver sido escolhido pela Administração.

Obviamente a audiência pública não é para que a Administração apresente categoricamente sua escolha, efetuada anteriormente e, cumpra, apenas e tão-somente, etapa formal.

Sua finalidade precípua é a ampla discussão, a ampla transparência, para que sejam exibidos os fundamentos necessários para o modelo escolhido e para que se ouça. se questione a possibilidade da proposição de outras formas.

Enfim, faz-se necessária intercomunicação. Não se trata de um monólogo, mas, sim, de diálogo entre as autoridades e os cidadãos.

5 Estamos a exemplificar com a licitação, porém nossas afirmaçōes seriam válidas no tocante aos processos em geral, que demandassem, nos termos da lei, inicialmente, audiência pública. 
Diz Jessé Torres, um dos melhores comentaristas da Lei de Licitações e Contratos, a propósito do tema que estamos a tratar de maneira específica:

"(...)

As audiências públicas integram o perfil caracterológico dos Estados Democráticos de Direito modelados pelo constitucionalismo europeu do pós-guerra, para o qual o poder político não apenas emana do povo e em seu nome é exercido (democracia representativa), mas comporta a participação direta do povo (a fórmula de democracia mista ou plebiscitaria inscrita no parágrafo único do art. $1^{\circ}$ da Constituição Federal de 1988).

\section{(..)}

Em face do vulto da licitação, compreende-se o intuito do legislador, contudo é preciso discernir-lhe o alcance. Não terá querido submeter ao crivo dos interessados a decisão de realizar o certame, por si só obrigatório, em princípio. Justifica-se a audiência para debater o objeto a ser licitado e o projeto proposto para a sua execução. Não haveria utilidade em rever com populares (presumidamente leigos) matéria que é estritamente técnicojurídica, quanto a se é devida, dispensável, inexigível ou vedada a licitação; a resposta encontra-se na Constituição e na legislação pertinente, e não em reuniões assembleares. O que seria passível de discussão aberta concerne ao teor político-administrativo do ato que delibera empreender o objeto e a como fazê-lo.

\section{(..)}

O novo estatuto, ao exigir a audiência pública antes da efetivação de concorrência de grande porte, pretendeu colher o assentimento, ou a reprovação, dos segmentos interessados no objeto (que será, no mais das vezes, obra ou serviço público de envergadura), seja quanto à conveniência ou à oportunidade de sua consecução, à vista das prioridades de aplicação dos recursos do erário, seja com respeito à concepção técnica e aos métodos de execução do respectivo projeto, que haverá de ser o mais sólido e menos oneroso para os cofres públicos. $" 6$

De seu turno, Marçal Justen Filho um dos mais profícuos comentadores da Lei de Licitações e Contratos, afirma:

“1) Publicidade e Fiscalização

O dispositivo confirma a concepção adotada pela Lei, no sentido de que a ampla publicidade é instrumento útil no controle da legalidade e da conveniência das licitações e contratações administrativas. Por isso, foi instituída essa audiência para hipóteses de contratações de maior vulto.

A audiência pública permitirá a qualquer "interessado" formular inda-

6 Jessé Torres Pereira Júnior, Comentários a Nova Lei das Licitações Públicas. Editora Renovar, Rio de Janeiro, 1993, p. 200-201. 
gações e pleitear esclarecimentos, os quais deverão ser prestados de modo motivado. Mesmo os aspectos discricionários da atividade administrativa poderão ser objeto de esclarecimento.

A lei não subordina a Administração à aprovação dos presentes à reunião pública. Não é relevante se os presentes reputam (ou não) que os esclarecimentos são satisfatórios. Os vícios, se não forem espontaneamente eliminados pela autoridade administrativa, autorizarão o recurso ao Poder Judiciário. Idêntica solução será viável quando a autoridade administrativa negar-se a prestar esclarecimentos.

\section{(...)}

A audiência pública é um dos instrumentos destinados a assegurar a transparência da atividade administrativa. Não se destina a garantir direitos subjetivos de pessoas determinadas, mas a proteger o interesse público, objetivamente. Logo, ausência ou invalidade da audiência acarreta nulidade do procedimento licitatório. Portanto, esse vício pode ser objeto de questionamento segundo os princípios relacionados com os interesses coletivos e difusos. Sujeita-se a controle por via de ação popular, ação civil pública Tc".? (grifamos)

E Gordillo acerca das audiências públicas, averbou:

“(..)

1.3. Audiencia pública y pública audiencia o sesión pública. Town Meetings

Cabe distinguir la "pública audiencia" o sesión pública para enfatizar que en la audiencia pública no se trata meramente de celebrar una sesión administrativa con asistencia pasiva y muda del público, radio, televisión, periodismo, etc., sino de realizar una audiencia en la cual el público es parte interesada y activa, com derechos de naturaleza procedimental a respetar dentro de la concepción ahora expandida del debido proceso constitucional: con derecho de ofrecer, producir prueba y controlar la que se produce, alegar, etc.

El concepto de participación pública es así esencial al de audiencia pública establecido por la ley, sin perjuicio de que además la audiencia debe estar abierta al conocimiento del público, periodismo etc. En ocasiones la legislación hace referencia meramente a "audiencias", pero de su contexto cabe interpretar que se trata de las mismas audiencias públicas aquí mentadas." 8

7 Marçal Justen Filho, Comentários à Lei de Licitações e Contratos Administrativos, Editora Dialética. São Paulo, 2000. p. 394.

8 Tratado de Derecho Administrativo, Tomo 2, La Defensa Del usuario Y Del Administrado, 4 * edición, Fundación de Derecho Administrativo, Buenos Aires, 2000, p. X1-8. 
9. Portanto, faz-se mister não esquecer, deixar limpidamente claro, estarmos diante de processo administrativo. processo licitatório. e, no exemplo trazido a contexto, processo licitatório, informado por princípios, princípios esses voltados a satisfazer integralmente o devido processo legal.

\section{Il - Os Princípios Específicos da Licitação}

10. Como já dissemos anteriormente, nas obras e serviços, que demandarem audiências públicas preliminares, é absolutamente importante que a audiência efetivamente preceda tais obras ou serviços. Estarão em confronto os princípios da legitimidade, economicidade e eficiência. como bem assinalados por Jessé Torres".

Torna-se importante, portanto, trazer a contexto os princípios da licitação, que estão arrolados no artigo $3^{\circ}$ da Lei $8.666 / 93$ com suas modificações. Tais princípios são: legalidade, impessoalidade, moralidade, igualdade, publicidade, probidade administrativa, vinculação ao edital, julgamento objetivo e demais principios, que lhes sejam correlatos.

Interessante notar que os princípios da Administração Pública, arrolados no artigo 37 da Constituição são: legalidade, moralidade, publicidade, impessoalidade e, pós-Emenda 19/98, eficiência.

Evidentemente que, além desses princípios explícitos, devem-se deixar claro os implícitos, co-naturais ao Estado Democrático de Direito. Não podemos, pois, olvidar da motivação, da razoabilidade, da boa fé, lealdade e do absoluto respeito ao devido processo .

Não podemos esquecer que, nessas formas de procedimento, é absolutamente imperioso para que se prossiga validamente, a conformidade do ato anterior. Todo ato deverá estar válido para possibilitar conduta posterior também válida.

Portanto, se, em determinadas obras, a uudiência pública deverá obrigatoriamente precedê-las, deverá ser executada de forma conforme. seguindo os cânones legais e principiológicos, atentando-se para a finalidade do instituto.

Ainda, para esse fim, devemos trazer à colação, mais uma vez, Agustín Gordillo:

“(...)

El incumplimiento o defectuoso cumplimiento del precepto de la audiencia pública es causal de nulidad absoluta e insanable del acto.

(...)

El hecho de que la administración deba realizar una audiencia pública, cuya materialidad - según veremos - debe adoptar buena parte de las formas de un proceso judicial oral, no debe llevar a confusión en cuanto a la índole de la función que en la especie se realiza: ella es siempre función administrativa, incluso el caso de los entes de regulación y control de servicios privatizados.

(...) 
Existe una estrecha relación entre los principios de contradicción y participación, por una parte y de oralidade e informalismo, por la otra. El debate en la audiencia pública debe, por su propia naturaleza, ser oral e informal, pero lógicamente ordenado por el órgano que preside la audiencia. Esto no requiere en modo alguno normas generales para todas las audiencias, sino que debe ser resuelto en cada caso singular conforme a los principios que informan este procedimiento ${ }^{10}$.

$$
\text { (...)". }
$$

III - Invalidação do Procedimento em virtude da audiência pública viciada: falta de razoabilidade, falta de motivação elou fatos supervenientes, que poderiam possibilitar escolhas administrativas diferentes

11. Se não se puder dizer ter existido verdadeiramente discussão sobre o modelo conceitual adotado por determinada Entidade Licitadora preliminarmente ao processo da licitação, mas, antes, a apresentação do modelo escolhido sem motivação suficiente para o fato de se haver decidido, por hipótese, até mesmo, modificar técnicas anteriores, que estivessem sendo adotadas com resultado satisfatório. o resultante de dita audiência terá sido praticamente monólogo e não diálogo.

Aliás, como sugerem, até mesmo, os vocábulos audiência e pública (lembremos descender do latim a palavra audiência, que vem de audire, e sua significação etimológica é ouvir) deverá necessariamente haver diálogo entre a Administração Pública e os participantes e não monólogo, sob pena de se frustar a participação popular.

12. De outra parte, também pode acontecer que supervenientemente (por exemplo, ocorrência de decisão judicial, que acolha a oposição de um dos participantes ao que se pretenda realizar) será imperiosa a renovação da audiência para a observância do principio da igualdade. Sim, da igualdade em face de todos os competidores, se não houver sido anulado todo o procedimento.

O sentido e alcance da audiência estariam, pois, frustrados, se não houver sido discutida, em audiência pública, a possibilidade de o serviço ou a obra também poderem ser realizados de outra maneira, razão, por hipótese, da oposição judicial de um dos interessados, que tenha obtido ganho de causa.

13. De outra parte, se houver defasagem de tempo entre a audiência pública, primeira fase do procedimento (enfatize-se, nessas obras de vulto), necessária a validar a imediatamente posterior, a publicação do edital, poder-se-á estar retirando sua finalidade precípua.

10 Idem, Ibid, p. XI 9-10. Veja-se. também, acerca do mesmo tema. Diogo de Figueiredo Moreira Neto. em Mutaçōes do Direito Administrativo, Renovar, Rio de Janeiro, 2000. 
13.1. Portanto, a razoabilidade e proporcionalidade poderiam ter sido desrespeitadas em face da defasagem temporal entre a realização da audiência pública e a publicação do edital.

O mesmo se diga diante de um licenciamento ambiental, urbanístico etc., quando as condições de fato possam ter se alterado.

13.2. Como não se decreta nulidade sem proveito - essa é a máxima faz-se necessário averiguar, em cada caso concreto, se houve fato hábil a fazer com que a audiência pública fosse considerada como não executada, nessas hipóteses.

Dito de outra forma, pode sempre infringir a razoabilidade defasagem temporal grande? Pode infringir a razoabilidade a maneira como efetuada a audiência? Pode infringir a razoabilidade caso se tenha tão-somente apresentado modelo conceitual acabado, produzido pela Administração Pública, e que não haja argumentos sólidos para sustentá-lo?

Deve-se atentar ao exato limite da importância da audiência pública no processo administrativo, que se estiver a tratar.

13.3. Todavia, não nos parece possível deixar de se refazerem as audiências públicas, quando obrigatórias para determinados procedimentos, considerando-as, apenas, como mais um mero requisito de formalidade do processo administrativo.

14. Acerca da proporcionalidade, verso e reverso do princípio da razoabilidade, elemento importantíssimo para aferição de se ter ou não cumprida a finalidade da audiência pública, afirma Paulo Bonavides e com a costumeira contundência:

\section{“(...)}

O princípio da proporcionalidade é, por conseguinte, direito positivo em nosso ordenamento constitucional. Embora não haja sido ainda formulado como "norma jurídica global", flui do espírito que anima em toda sua extensão e profundidade o $\S 2^{\circ}$ do art. $5^{\circ}$, o qual abrange a parte não-escrita ou não expressa dos direitos e garantias da Constituição, a saber, aqueles direitos e garantias cujo fundamento decorre da natureza do regime, da essência impostergável do Estado de Direito e dos princípios que este consagra e que fazem inviolável a unidade da Constituição.

Poder-se-á enfim dizer, a esta altura, que o princípio da proporcionalidade é hoje axioma do Direito Constitucional, corolário da constitucionalidade e cânone do Estado de direito, bem como regra que tolhe cada sistema legítimo de autoridade. A ele não poderia ficar estranho, pois, o Direito Constitucional brasileiro. Sendo como é, princípio que embarga o próprio alargamento dos limites do Estado ao legislar sobre matéria que abrange direta ou indiretamente o exercício da liberdade e dos direitos fundamentais, mister se faz proclamar a força cogente de sua normatividade."

11 Paulo BONAVIDES. "Curso de Direito Constitucional", $11^{\text {a }}$ edição/2001, revista, atualizada e ampliada, Malheiros Editores, São Paulo, p. 396-397. 
14.1. Ainda é Diogo de Figueiredo Moreira Neto ${ }^{12}$ quem averba:

“(...)

Mas além dos princípios de expresso assento constitucional referidos, outros existem, inferíveis, todos realçados pela doutrina, que concorrem para informar a audiência pública e firmar-lhe os contornos jurídicos, como o da realidade o da lealdade, o da motivação, o da proporcionalidade e o da prevenção de litígios.

(...)

O princípio da proporcionalidade, que também pode ser considerado como um aspecto do princípio, mais geral, da razoabilidade, transmite um sentido finalístico ao processo da audiência pública de modo a limitar o máximo dos sacrifícios gerais advenientes da ação administrativa às correlatas vantagens coletivas esperadas, bem como, a limitar o máximo de sacrifício individual porventura exigido, a uma correspondente compensação, individual ou coletivamente auferida.

Ainda aqui, cabe uma referência ao princípio da prevenção de litígios, prudente concepção que recomenda esgotar-se todo elenco de meios com o fito de evitarem se os inúmeros inconvenientes dos conflitos e das demandas. A audiência pública concorre positivamente para que as fontes de litígios sejam pré-identificadas e as possíveis soluções, equacionadas e até adiantadas." (grifos do original)

Pensando-se na força cogente do princípio da razoabilidade, e de seu corolário lógico, a proporcionalidade ${ }^{13}$, parece-nos claro, como afirma Jessé Torres Pereira, que, sem se discutir efetivamente as possibilidades para a realização do melhor contrato, a fim de a Administração Pública vir a poder celebrá-lo, necessário se faz para evitar vício insanável posteriormente, o refazimento completo do procedimento, portanto, desde seu ato inicial a preceder o edital.

Quando a Lei 8.666/93, em seu artigo 39. dispõe que a audiência pública deverá ser celebrada com o mínimo de 15 dias de antecedência, pretendeu a existência de tempo suficiente para que, depois da oitiva dos interessados, pudessem ser apresentadas propostas "serias e firmes", como diz Marcelo Caetano.

Obviamente. não fixa a Lei o tempo máximo a preceder o processo administrativo, mas subentende-se perfeitamente: não pode haver lapso temporal demasiadamente grande porque, por óbvio, as circunstâncias factuais, podem ser alteradas.

\footnotetext{
12 Ob. Cit. p. 19

13 Todavia, apesar de dizermos que a proporcionalidade é o corolário lógico da razoabilidade. entendemos que há certa diferença. que, brevemente, trazemos à colaçāo. A razoabilidade é um standard, o parâmetro médio de certa situação. enquanto que, na proporcionalidade há de acrescentar um plus. Com efeito. alguma coisa pode ser razoável, porém não estar em estrita proporcionalidade com a finalidade perseguida. ou por ser excessiva, ou, então. por ser inferior ao que deveria ser na situaçāo concreta.
} 
O processo administrativo não pode se interromper por tanto tempo, como se nada houvesse acontecido, e prosseguir como se tudo estivesse absolutamente dentro da normalidade, respeitando-se os princípios da razoabilidade, da legitimidade e do devido processo legal.

15. Depois da Constituição de 1988, as funções dos Tribunais de Contas foram ampliadas e, certamente, a esse controlador, não cabe mais, apenas e tão-somente, o papel de "chancelador" de papéis formais. Os atos praticados devem ser examinados em sua plenitude para verificação do cumprimento dos princípios constitucionais e legais.

15.1. E, esses, princípios, constitucionais e legais, certamente devem ser cumpridos em sua plenitude. A Administração, no Estado de Direito. somente pode agir sub legem. E, note-se que quando se diz sub legem não mais se quer dizer apenas debaixo da lei específica.

Como já tivemos ocasião de apostilar: o princípio da legalidade é muito mais amplo. Legalidade significa estar de acordo com a Constituição e com os princípios vetoriais do ordenamento jurídico. Portanto, trata-se do princípio da constitucionalidade.

A Administração Pública deve agir com eficiência, segundo a Emenda Constitucional 19/98. Agir com eficiência significa contemplar todas as possibilidades de obter o melhor contrato, a melhor decisão (sobretudo legítima por obter o consenso dos administrados), possibilitando. sem dúvida, que se discuta amplamente os modelos e que, ademais, tais modelos possam estar estribados em fortes elementos de conviç̧ão e nunca dependerem de escolhas discricionárias, sem limites, portanto. até arbitrárias da Administração, sem peias ou amarras.

É preciso que a Administração conte com a efetiva colaboração popular, a afim de que haja administração concertada, administração participativa, consensual.

Passamos a breve síntese do que, até agora, foi dito.

1. A finalidade da audiência pública, seguindo-se a orientação, hoje quase mundial, é de transparência da Administração, de lealdade, de fair play na conduta administrativa. Considera-se que, se a Constituição prescreve uma atuação participativa, como afirma Gordillo ${ }^{14}$, mesmo sem obrigatoriedade constitucional ou legal, grandes projetos ou decisões importantes a serem tomadas, necessariamente deveriam ser precedidos de audiência pública.

Todavia, a audiência pública não pode ser mera formalidade, mas, verdadeiramente, deve-se constituir no meio pelo qual decisões vão ser tomadas, depois de se dar oportunidade de efetivamente OUVIR (audire) os interessados.

E, certamente, se a lei impuser a audiência pública, afigura-se que sua falta, ou, então, sua realização de forma viciada, invalida o procedimento.

A audiência pública, se convenientemente executada, trará legitimidade e eficiência para as decisões administrativas tomadas. 
Ademais quando seja ela obrigatória, como no direito brasileiro em várias leis, é parte de um processo - e, como tal, há de se aplicar na sua inteireza o devido processo com todos os princípios que the são inerentes e, especificamente, onde houver omissão em lei específica, se estivermos diante de processos de âmbito federal. dever-se-á aplicar a Lei 9.784, de 29.01.1999, que regula o processo administrativo no âmbito da Administração Pública Federal, lei essa, que prevê, expressamente, a audiência pública.

1.1. Obviamente, se assim se considerar, deve-se processar a audiência, repitase, não como formalidade a ser cumprida para que não haja nulidade, mas, sim, com o objetivo de legitimar as ações administrativas, as opções administrativas, visando a dar transparência à Administração e, por meio dela, trazer a tão desejada eficiência, fugindo-se da corrupção administrativa, infelizmente prática mais comum do que seria tolerável num país atento aos princípios democráticos.

1.2. A audiência pública. prática surgida no direito anglo-saxônico, adquire sua expressão maior no direito americano como right to a fair hearing.

Em consequiência. por óbvio, os princípios constitucionais devem ser respeitados para se procedê-la validamente, não somente como princípio constitucional de participação da cidadania. mas como legalmente obrigatória. nos termos de legislações específicas, e no caso abordado de obras de vulto, do artigo 39 da Lei 8.666/93.

2. De outra parte, se obrigatória, como, nessas hipóteses abordadas, deverá se constituir em etapa primeira do procedimento, não se deverá realizar em data muito anterior à decisão a se tomar, porque, na maioria das vezes, perderia sua finalidade. A defasagem temporal faria com que certas condições de fato pudessem ser modificadas, portanto, a audiência necessária. o fair hearing. não teria sido cumprido.

E, evidentemente, se essa defasagem temporal trouxer, como consequiência, condições de fato novas, poderá haver nulidade do procedimento.

Tratar-se-ia, na verdade de arremedo de audiência. que, aparentemente teria cumprido sua finalidade, porém, perde-a, porque a marcha para frente do processo não terá sido devidamente executada.

3. Temos enfatizado ser a motivação de suma importância no direito administrativo. Valida ou invalida o ato administrativo. E, na hipótese da audiência pública. sobretudo se a conclusão dos participantes for em sentido oposto ao decidido pela Administração, é vital para se aferir as razões de a Administração Pública ter rejeitado o "veto" dos partícipes.

3.1. Infelizmente, nossa Administração ainda não detectou, passados quase treze anos do novo modelo constitucional, que deve se jungir à Constituição, a seus princípios vetoriais, à lei. e, definitivamente, curvar-se ao devido processo legal, fundamento último do Estado de Direito.

Não detectou ainda serem a transparência, a motivação, postulados fundamentais do Estado Democrático de Direito. 


\section{Questões de Direito Positivo}

N. Doreste Baptista,

Renato Maneschy, Carlos Alberto Direito

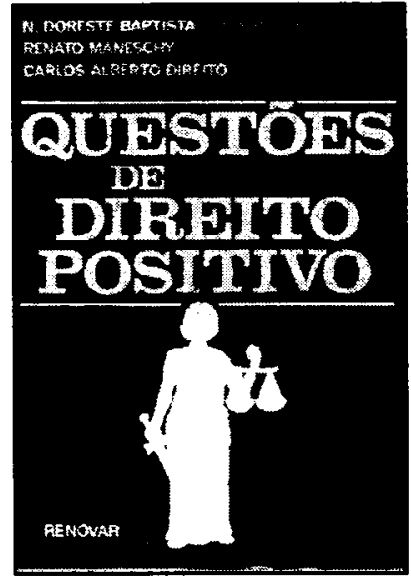

Os autores reuniram acórdãos e votos selecionados de três excelentes julgadores, Desembargadores do Tribunal de Justiça do Estado do Rio de Janeiro, que, inobstante a quantidade exaustiva de processos e trabalhos, conseguem nào só manter em dia os serviços, como estudar e produzir soluçōes jurídicas altamente apreciáveis.

Ref. 0018

Form. 14x21

Brochura

1990

330 págs.

\section{Reforma das S.A. e do Mercado de Capitais}

O presente livro apresenta uma análise profunda e detalhada das principais modificaçōes introduzidas em nosso direito societário mediante a reforma da Lei das S.A. e da Lei do Mercado de Capitais. Constitui, pois, indispensável material de consulta para juizes, adrogados, estudantes de Direito, assim como para os profissionais que atuam em setores empresariais e no mercado de capitais.

Ref. 0142

Form. 14x21
Brochura 1997
448 págs. $2^{\mathbf{a}}$ ed.

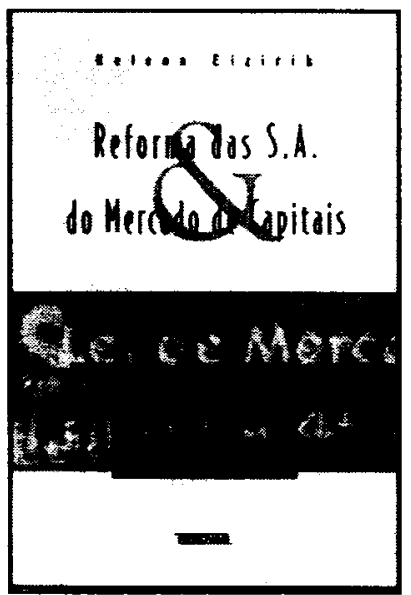

